\title{
Assessment of skill gap and factors influencing career choice among fisheries graduates in India
}

\author{
K. GREENSEA, M. KRISHNAN, V. SARAVANAKUMAR*, SWADESH PRAKASH, \\ P. S. ANANTHAN AND NEHA QURESHI \\ ICAR-Central Institute of Fisheries Education, Mumbai - 400 061, Maharashtra, India \\ "Department of Agricultural Economics, Tamil Nadu Agricultural University, Coimbatore - 641 003, Tamil Nadu, India \\ e-mail:mkrishnan@cife.edu.in
}

\begin{abstract}
The paper reports the result of an assessment of career choice among fisheries graduates and skill gap between expectations of employers and employees in India. Qualitative and quantitative data were collected from the fisheries students (employees) and employers through survey. The results revealed that there are differences between factors influencing career choice of males and females with reference to two factors namely, previous job experience and family status. The employers-employees survey revealed that there exists a gap in technical skills which should be given focus to increase competency among employees to match the expectations of the employer. There is an indication of emerging demand for fisheries professionals to cater the needs of employers in fisheries sector.
\end{abstract}

Keywords: Career choice, Employees, Employers, Fisheries graduates, Skill gap

\section{Introduction}

India is a democratic country and follows the mixed economy model. It has emerged progressively from a low-income country to a middle-income one since independence. Interestingly, social indicators of India with a Human Development Index Ranking of 134, are well above the same parameters in developing countries in South Asia (ILO, 2008).

There is a high demand for skilled and educated workforce in India. They are sought by all government departments and private sector. Though, there are plenty of opportunities for employment in India there is always a question whether the output of the education institutions commensurate with the requirements of the sectors to whom they cater to. Rashmi Agrawal et al. (2016), opined that job prospects of job seekers affects both spread of employment as well as skill required for the particular job.

The sector-wise contribution of Indian economy has changed from an agriculture-based economy to the service based economy. The service sector has the highest contribution to GDP in 2015, with $59.97 \%$, followed by the industrial sector at $30.02 \%$ and the agricultural sector at $17 \%$. The economic liberalisation made the services sector to become the largest sector in terms of employment providing $43.1 \%$ employment. However, primary sector remains the strategic source of employment in rural areas.

There has been an increase in non-core employment of the workforce. The growth has resulted in creation of non-farm employment. But it is felt that most of the employment has been in the non-core and insecure areas (ILO, 2008).

Fisheries sector plays an important role in national economy and in the socio-economic development of the country. The total fish production of India during 2014-15 was 10.69 million $t$ and as many as 14.90 million persons in the country depend on fisheries sector for their livelihood. It is one of the potential sectors to focus for economic development. In order to propel and uplift the fisheries sector, the thrust could be given to development of skills to empower the fisheries sector.

Qualified and trained manpower is a vital input for fisheries research and development. Education produces knowledge-empowered individuals who are responsible for sustenance of productivity, growth, food security, alleviation of poverty and unemployment besides devising resourceful and effective delivery systems for the benefits of society.

Large number of researchers have reported qualified manpower requirements in the fisheries sector. According to their estimates, it ranges from few thousands to hundreds of thousands of persons with various skills, training and education levels (Chidambaram, 1985; Kohli, 1998; Ayyappan and Biradar, 2000)

The present study documents the factors which influence career choice of fisheries graduates and the mismatches between expectations of fisheries students 
(employee) and employers. This study aims to provide the fisheries education system empirical evidence to substantiate the need for reforms to enable desired modifications in the curriculum and skill sets actually required by the fisheries sector at the user level. Therefore, the results of this research provide a bench mark of the attitudes, perception of skills and the requirements at the field level.

\section{Materials and methods}

Information about the factors influencing career choice among fisheries graduates were collected randomly with the help of a questionnaire using binary format. The targeted sample to estimate career influencing factors were employed fisheries professionals graduated from professional fisheries colleges in India. Therefore, four fisheries colleges were selected on the basis of location and corresponding state, central, deemed university basis to represent employed fisheries professional all over India. The data were primarily dichotomous except income which is continuous variable. The sample consisted of 81 employed graduates of four fisheries colleges namely Fisheries College and Research Institute, Tuticorin (State Fisheries University), College of Fisheries, Lembucherra (Central Agricultural University), College of Fisheries Science, Pantnagar (State Agricultural University) and Central Institute of Fisheries Education, Mumbai (Deemed University). Categorical variables were employed on multivariate logit regression model to establish the relative factor influencing the choice of career. The differences in factors influencing career choice of male and female graduates were tested using Mann-Whitney U tests. The main survey was carried out between August to October 2016. In order to increase the number of responses, questionnaires were mailed and telephonic interviews were also adopted.

Data on the apparent mismatch between the expectations of skill sets of the employers and fisheries students (employee) of four fisheries colleges were studied based on rating of skills. The employees were the students of fisheries professional colleges who were presently pursing undergraduation, postgraduation as well as doctoral and postdoctoral programs and employers were universities, research organisations, other academic institutions, extension institutions, state fisheries departments including the fisheries private sector. The mismatch was evaluated by administering different sets of questionnaires using specific parallel questions to confirm the reliability of the instrument employed for data collection. The research instrument were provided to 147 fisheries students (employee) and 41 employers (universities, research and academic institutions, fisheries private sector and state fisheries departments) to allow clear comparison between expectations of employers and employees. Guvenen et al. (2015) and Liu, K et al. (2016) employed survey instruments based determination to evaluate the multidimensional skill mismatch. Ranking was used to evaluate the mismatch between the expectation of employer and employee by using the Rank Based Quotient (RBQ) which were estimated using the formula:

$$
\mathrm{RBQ}=\sum\left[\mathrm{F}_{\mathrm{i}}(\mathrm{n}+1)-\mathrm{i}\right] /\left(\mathrm{N}^{*} \mathrm{n}\right)^{*} 100
$$

where, $F_{i}=$ Number of respondents giving the particular point at $\mathrm{i}^{\text {th }}$ rank, $\mathrm{I}=\mathrm{i}^{\text {th }}$ rank, $\mathrm{N}=$ Total number of respondents, $\mathrm{n}=$ No. of factors

This method was used for analysing expectation factors of fisheries sector and fisheries graduates. The respondents were asked to rank the factors, which fisheries sector and fisheries graduates expected from each other. Again, in order to understand the factors influencing the choice of career among males and females, logit regression was used. The representation of the function is given by the formula:

$$
\mathrm{F}(\mathrm{x})=1 / 1+\mathrm{e}^{-(\beta+\beta \mathrm{x})}
$$

Note that $\mathrm{F}(\mathrm{x})$ is interpreted as the probability of the dependent variable equaling a "success" or "case" rather than a failure or non-case. It is clear that the response variables $\mathrm{Y}_{\mathrm{i}}$ are not identically distributed. $\mathrm{P}(\mathrm{Xi}=1 / \mathrm{X})$ differs from one data point $X_{I}$ to another, though they are independent, given design matrix $\mathrm{X}$ and shared with parameters (Mitchel and Carson, 1989; George et al., 2005; Sivasakthi et al., 2006; Qureshi et al., 2016).

\section{Results and discussion}

Fisheries graduates employed in different avocation were selected for identifying factors influencing career choice. Table 1 compares the determinants of career choice for male and female fisheries graduates. Number of parameters were selected to determine the factors that influence the career choice. They included skills and abilities, education and training, passion for the job, providence, family status and previous experience. The mean values were estimated for male and female separately based on Mann-Whitney U test. As far as males were concerned, previous job experience emerged as the most significant factor that influenced their career choice $($ mean value $=54.14)$. The mean value of other parameters that followed in sequence were: family status (51.41), providence (41.22), education and training (38.72), skills and abilities (38.49) and passion for the job (37.79). Therefore, it can be seen that, experience followed by family status were the factors that has the greatest influence on the choice of career of male fisheries graduates.

As far as female fisheries graduates were: concerned, passion (43.84), followed by skills and abilities (43.22), education and training (43.01), providence (40.80), family 
Table 1. Comparison on determinants of career choice between male and female graduates

\begin{tabular}{lllll}
\hline \multirow{2}{*}{ Variable } & \multicolumn{2}{c}{ Mean value } & \multirow{2}{*}{ p value } & \multirow{2}{*}{ Decision } \\
\cline { 2 - 3 } & Male & Female & & \\
\hline Skills and abilities & 38.49 & 43.22 & 0.295 & Ho is not rejected \\
Education and training & 38.72 & 43.01 & 0.320 & Ho is not rejected \\
Passion for the job & 37.79 & 43.84 & 0.173 & Ho is not rejected \\
Providence & 41.22 & 40.80 & 0.918 & Ho is not rejected \\
Family status & 51.41 & 31.80 & $<0.001^{* *}$ & Ho is rejected \\
Experience from previous job & 54.14 & 29.38 & $<0.001^{* *}$ & Ho is rejected \\
\hline
\end{tabular}

${ }^{* *}$ Significance at $1 \%$ level

status (31.80) and previous experience (29.38) were the factors that influenced the choice of career among female fisheries graduates.

Mann-Whitney test results revealed that family status and previous job experience were the only significant determinants of career choice between male and female graduates under consideration. As stated earlier, in order to establish any skill mismatch between employers and fisheries students in terms of requirements, a set of parameters were identified to evaluate the extent of skill mismatch. RBQ was estimated based on the ranks for the parameters expressed by the graduates and the employers. (Fig. 1).

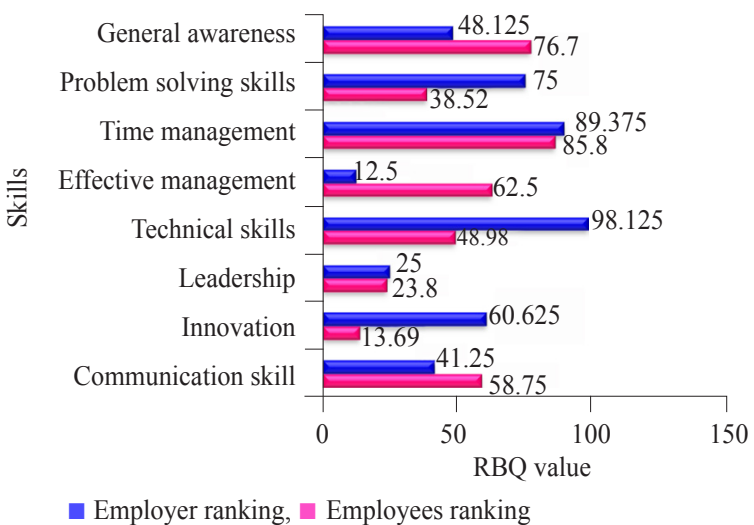

Fig. 1.Skill mismatch between employers and employees. Reflects a strong mismatch between the expectations of employers and those of the employees (Fisheries students) Employers included academic and research institutions and fisheries private sector companies. Employees were students at different stages of completion of their fisheries education

The parameters that were used for estimating the skill mismatch included communication skills, innovation, leadership, technical skill, effective management, ability, time management, problem solving skills and general awareness. As far as skill mismatch was concerned the biggest gap in skills required by employers and fisheries graduates was technical skill. There was a gap of almost $50 \%$ between the expectation and fulfillment of skills. The gap was also large in case of effective management ability $(40 \%)$. In the case of this parameter, it may be noted that the capacity for effective management of the students was much more than what was expected of them by their employers. With respect to innovations, the innovative capacity of the fisheries graduates was $47 \%$ less than what was expected of them by their employers. In the case of communication, general awareness and leadership in effective management and the capacity of the students were in excess of that required by their employers. But in case of problem solving skills and time management under innovations, the students fell short of the expectations of their employers.

The above discussion indicates that the skills of the fisheries graduates were more than what was required by the fisheries sector in non-core areas and less so in core areas. Therefore, it is felt that the employability of the fisheries graduates will improve dramatically if the skills were honed better in core skills like technical, innovation, and problem solving abilities (Fig. 2).

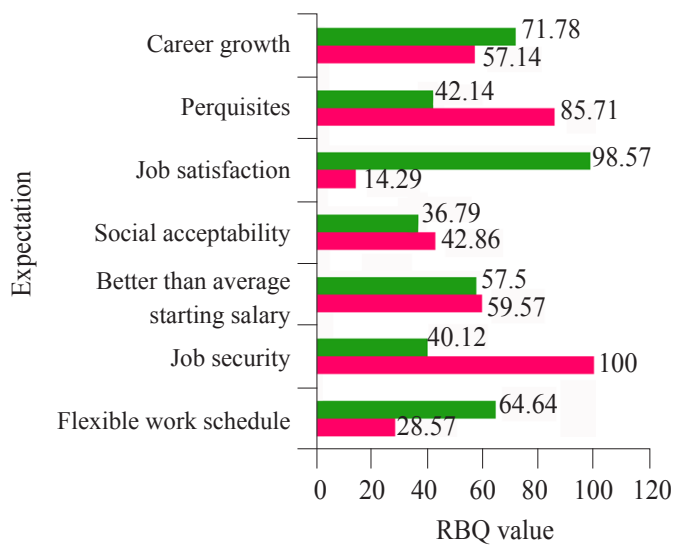

— Employer RBQ value, Employees RBQ value

Fig. 2.Rating of expectations of employers and employees (graduates). Shows the mismatch of expectations of the employers and employees. RBQ was employed to rank the expectations of employers and employees. The parameters included, flexible work schedule, job security, above (sector) average salary, social acceptability, job satisfaction, perquisites and career growth 
As far as job security, perquisites and social acceptability are concerned, the expectations of fisheries graduates were much higher compared to what the sector could offer. But, as far as flexible work schedule, job satisfaction and career growth were concerned, the offers of the employers were higher than what the graduates expected. The expectations of graduates and what the employer had on offer matched in case of the average sector salary.

Therefore, it can be seen that the employer's outlook was modern and innovative and they were prepared to pay good salary as well as perquisites to the graduates to meet their expectations. The rating also revealed that the attitude of the graduates and their outlook required an improvement.

Hosmer and Lemeshow test showed insignificant result at level of significance of 0.202 and revealed that this model is a good fit. Table 2 gives the regression estimates of multivariate regression model for deciding career choice. Based on the standard inferences that emerged out of a multivariate logit model, log odds ratio in favour of family background exerted a 3\% influence on career choice of a permanent job which indicated that family background (status) had a positive influence on making the career choice of selecting a permanent job. The log odds for job experience showed 29\% positive impact for temporary job selection which implies that previous job experience was the positive factor providing 29 times increased opportunity to choose and avail a temporary job. Log odds ratio for employment as desired (passion), works out to $0.6 \%$ against the probability of the student getting into the career of choice, providing ethical reason that passion toward getting a job did not have positive effect, rather has the negative effect by diverting the professional to non-passionate area of interest in job decision.

With regard to career choice, family status was a deciding factor in case of males. On the other hand, females decided their job based on their ability and passion. Wilkinson (1996) also found that there is significant difference between male and female gender and it is the major factor which influenced the career choice even though, on the whole these factors rank low in their importance.

This study highlighted the differences between the expectations of employers and graduates. It was observed that among the eight factors studied, employers gave maximum importance to technical skill followed by time management, problem solving skills, innovativeness of candidates, awareness of changes that would impact their organisation, communication skills, leadership and finally effective management of resources. However, there existed a difference in availability of these desired skills in the fisheries workforce. The candidates were best in time management followed by awareness of changes impacting the organisation, effective management of resources and communication skill. Although technical skill was the most favoured quality for the employers, huge gap was observed among the candidates. It is to be noted that innovation and problem solving skill increases with increase in the technical skill. An interesting fact of the survey was the low desirability of an important quality of leadership by the employers. At the same time, leadership skills of the graduates was found to be low as far as employer expectation is concerned. Blom (2011) reported that there is always skill shortage existing in Indian economy. Green (2009) opined that occupation-specific knowledge and technical skills could make graduates competitive in the labour market and increase job opportunities availed by them and maintain employability.

In UK, fisheries technical education is normally given to candidates sponsored by the aquaculture or processing sectors leading to matching of supply and demand for qualified technical personnel in fisheries. As against the readiness of the institutions to train the employees of the fisheries sector in production, processing, value addition, marketing and exports, the Indian education system seems to be more focused on generating fisheries graduates in anticipation of their absorption by the industry. The study showed that this approach is skewed to producing graduates who may not be meeting the requirements of the industry and other subsectors. Therefore this study does

Table 2. Regression estimates of multivariate logit model for career choice

\begin{tabular}{llllll}
\hline Factors & Coefficient & Standard error & Wald cofficient & Levels of significance & Exponential of $(\beta)$ \\
\hline Family Status & 1.367 & 0.632 & 4.679 & $0.031^{*}$ & 3.922 \\
Job experience & 3.376 & 0.928 & 13.242 & $<0.001^{* *}$ & 29.249 \\
Skills & -.580 & 0.636 & 0.830 & 0.362 & 0.560 \\
Education & -.433 & 0.695 & 0.388 & 0.533 & 0.285 \\
Passion & -1.257 & 0.771 & 2.660 & $0.023^{*}$ & 0.649 \\
Income & .000 & 0.000 & 0.158 & 0.691 & 1.000 \\
Constant & -1.633 & 1.152 & 2.008 & 0.156 & 0.195
\end{tabular}

"significant at $5 \%,{ }^{* *}$ significant at $1 \%$ level 
bring to fore a dire need to restructure fisheries education in India. This study provides some leads into the gaps that exist between the skill requirement of the industry and that which fisheries education currently provides through their graduates. It is beyond the scope of this work to make any comment on how this restructuring in fisheries education needs to be made to bridge the existing divide in requirements of the industry and skills possessed by the fisheries graduates.

\section{Acknowledgements}

The authors are grateful to the Director, ICAR-CIFE, Mumbai for continuous support and encouragement during the course of the study. The first author acknowledges the financial support obtained under the ICAR-JRF financial scheme.

\section{References}

Ayyappan, S. and Biradar, R. S. 2000. Manpower requirements and human resource development in fisheries sector. Report of the brainstorming session, Education Division of Indian Council of Agricultural Research, New Delhi and Central Institute of Fisheries Education, 20-21 October 2000, ICAR-Central Institute of Fisheries Education, Mumbai, India.

Blom, A. and Saeki, H. 2011. Employability and skill set of newly graduated engineers in India. World Bank Policy Research Working Paper Series.

Chidambaram, K. 1985. Manpower planning: an assessment for the next decade. In: Kulkarni,G. R. and Srivastava, U. K. (Eds.), A systems framework of the marine foods industry in India. Concept publishing Co., New Delhi, p. 333-374.

George Matiya, Yoshikazu Wakabayashi, Davies Ng'ong'ola and Naruhito Takenouchi 2005. A logit analysis of socio-economic factors influencing people to become fisherman around Lake Malombe in Malawi. J. Appl. Sci. Res., 1(1): 18-23.

Green, F. 2009. The growing importance of generic skills. Document commissioned as part of the UK Department for Children, Schools and Families, Beyond Current Horizons project, Futurelab.

Guvenen, F., Kuruscu, B., Tanaka, S. and Wiczer, D 2015. Multidimensional skill mismatch (No. w21376) National Bureau of Economic Research.

ILO 2008. Decent Work Country Programme 2008-2012.

Kohli, M. P. S. 1998. Manpower requirements in Indian fisheries sector. Fishing Chimes, 18(2): 42.

Liu, K., Salvanes, K. G. and Sorensen, E. O. 2016. Good skills in bad times: Cyclical skill mismatch and the long-term effects of graduating in a recession. European Econ. Rev., 84: 3-17.

Qureshi Neha, W., Krishnan, M. and Sundaramoorthy, C. 2016. 'Fish for all' versus 'fish of choice' - growth, instability and stakeholders' responses for enhancing fish production in major lakes of Kashmir, Curr. Sci., 110(8): 1495-1504.

Rashmi Agarwal, Rama Rao Darapuneni, Banda, V. L. N. Rao, Nanda, S. K. and Sanchita Bhattacharya 2016. Assessment of employment potential of fisheries professionals in India. Indian J. Fish., 63(2): 102-109.

Sivasakthi Devi, T., Ramasamy, C. and Gurunathan, S. 2006. Farmer's willingness to pay to avert the negative externalities of pollution of dyeing industry in Tamil Nadu. Agric. Econ. Res. Rev., 23: 245-252.

Wilkinson, S. 1996. The factors affecting the career choice of male and female civil engineering students in the UK. Career Dev. Int., 1(5): p.45-50. 